\title{
The Situation Specific Arousal Analyzer: Innovation in the Physiological Assessment of Foreign Language Education Anxiety
}

\author{
Damian J. Rivers* \\ Future University Hakodate, Hakodate, Japan
}

As the most studied affective variable within foreign language education, the emotion of anxiety continues to generate significant research interest. Owing to technological developments in wearable research devices, new opportunities have arisen to expand the research methodologies used in the recording and assessment of foreign language education anxiety. This article contends that foreign language education research has over-emphasized the experiential component of emotion while neglecting the behavioural and physiological components. Attention is first given to the emergence of emotion as a significant focal point in foreign language education. The position of anxiety as an affective

OPEN ACCESS

Edited by:

Agnes Kukulska-Hulme, The Open University, United Kingdom

Reviewed by:

Zsuzsanna Bárkányi,

The Open University, United Kingdom Xian Zhang, University of North Texas, United States

*Correspondence: Damian J. Rivers rivers@fun.ac.jp

Specialty section: This article was submitted to Digital Learning Innovations,

a section of the journal Frontiers in Education

Received: 27 October 2021 Accepted: 06 January 2022 Published: 01 February 2022

Citation:

Rivers DJ (2022) The Situation Specific Arousal Analyzer: Innovation in the Physiological Assessment of Foreign Language Education Anxiety. Front. Educ. 7:802639. doi: 10.3389/feduc.2022.802639 variable in foreign language education is then documented along with the methodological limitations of experiential measures. The article then highlights technological innovations in physiological data measurement and analysis in the form of the Empatica E4 wristband and the recent development of the Situation Specific Arousal Analyzer (SSAA) application. The article demonstrates how foreign language education anxiety researchers can use the Empatica E4 and SSAA to document autonomic nervous system arousal in real-time communication situations using high-integrity metrics such as Heart Rate Variability (HRV) and Electrodermal Activity (EDA) under a range of tailored conditions. The article ends with a call to foreign language education anxiety researchers to extend their methodological repertoire beyond experiential self-report measures and to consider the opportunities afforded by physiological data capture and analysis technologies.

Keywords: anxiety, arousal, foreign language education, methodologies, physiological assessment

\section{INTRODUCTION}

Almost two decades prior an article was published entitled "predicting autonomic reactivity to public speaking: don't get fixed on self-report data!" (Schwerdtfeger, 2004) in which the author cautioned that self-report measures of emotionality often fail to align with autonomic reactivity assessments. More recently, prominent researchers have championed the "lift-off of emotion research in applied linguistics" (Dewaele, 2019) and shifts toward the greater inclusion of educational psychology within the remit of foreign language education have produced several studies examining the affective role of emotions (Zheng and Cheng, 2018; Dewaele et al., 2019; Li, 2019; Li et al., 2019; Botes et al., 2020; Dewaele and Li, 2020; Chen et al., 2021; Dewaele and Pavelescu, 2021; Li et al., 2021; Pan and Zhang, 2021). It has long been known that emotions are "influenced by internal physiological processes" (MacIntyre, 2017, p. 28) and "call forth a coordinated set of behavioral, experiential, and 
physiological response tendencies that together influence how we respond to perceived challenges and opportunities" (Gross, 2002, p. 281). However, rather than taking flight, the research methodologies used to isolate, capture, define and analyze emotions have remained grounded and based upon the recalled documentation of personal experience.

This reflects a constructivist belief that emotions can sufficiently be understood on a social level of analysis. This trend is evident in foreign language education research wherein the experiential components of emotion (self-reports, interviews, narratives) have been emphasized while the behavioural (speech characteristics, facial expressions, gestures, movements) and, to a much greater extent, the physiological components (autonomic nervous system arousal) have been marginalized. Such limitations have reinforced the perception that emotions continue to be "poorly studied and poorly understood" (Swain, 2013, p. 195).

As research into emotion is now an interdisciplinary undertaking supported by technological innovation, a recalibration of research methodology is required for the benefit of students, teachers, and the integrity of future research output. This article therefore draws attention to the research methodologies used to isolate, capture, define and analyze anxiety within foreign language education. Attention is directed toward technological innovations in physiological data measurement and analysis informed by the premise that "conscious emotional experience is closely bound to changes in bodily sensations. Indeed, if one accepts the notion that consciousness is grounded in biological processes ... emotional experience must, by its nature, be physiological" (Pace-Schott et al., 2019 , p. 267). To this end, the article highlights advancements made in the health tracking provisions of wearable wristbands with a focus on the Empatica E4, a "medical-grade wearable device that offers real-time physiological data acquisition, enabling researchers to conduct in-depth analysis and visualization" (Empatica Inc., 2021). This article showcases how foreign language education researchers can use the device to document autonomic nervous system arousal in real-time communication situations using highintegrity metrics such as Heart Rate Variability (HRV) and Electrodermal Activity (EDA). To facilitate the uptake of such technological innovations among non-clinical practitioners, this article further introduces the Situation Specific Arousal Analyzer (SSAA) application. The SSAA allows practitioners to analyze physiological arousal under a range of tailored conditions focused on either the micro analysis of arousal in time specific segments (e.g., assessed every few seconds across the duration of an L2 spoken presentation) or relative to longer macro periods of analysis (e.g., assessed across an entire classroom period). The article ends with a call to foreign language education anxiety researchers to extend their methodological repertoire beyond experiential self-report measures and to consider the opportunities afforded by physiological data capture and analysis technologies.

\section{Anxiety in Foreign Language Education}

Since the mid 1980s research attention within foreign language education has fixated on the emotion of anxiety and its negative impact upon the language learner (Aida, 1994; MacIntyre and Gardner, 1994; Onwuegbuzie et al., 1999; Gregersen and Horwitz, 2002; Dewaele et al., 2008). Drawing attention to the experiential and physiological components of anxiety, the American Psychological Association (2021) defines the emotion as being "characterized by feelings of tension, worried thoughts and physical changes like increased blood pressure". While the physiological properties of anxiety may be universal, the situational onset of anxiety lends itself to a basic distinction between trait anxiety and state anxiety. This distinction is significant in that "many investigations use the word 'anxiety' without being specific about what they are talking about" (Robinson et al., 2013, p. 14). Trait anxiety denotes a relatively stable feature of an individual's personality profile and reflects a predisposition to psychopathological conditions and heightened states of arousal such as panic attacks, whereas state anxiety or experimentally-induced anxiety is a more temporal situation-specific experience (Spielberger et al., 1983) often occurring in the absence of underlying psychopathological conditions. As a response to environmental stimuli, anxiety is a particularly important emotion due to its evolutionary function in survival and the avoidance of threat. The underlying mechanisms concerning the processing of environmental stimuli as threatening also informs conditions such as social anxiety disorder, agoraphobia, and a range of panic disorders which now constitute a considerable worldwide burden having social and economic consequence. Emotions which relate to evolutionary survival are more likely to be inclusive of physiological activity as the body prepares to defend itself or flea the perceived threat. Researchers have used this to explain why certain emotions such as happiness and joy often have no accompanying physiological profile (Levenson, 2003).

Prompted by the seminal work of Horwitz et al. (1986) and the Foreign Language Classroom Anxiety Scale (FLCAS), state anxiety has developed into the most studied affective variable in foreign language education research. Horwitz et al. (1986) detail how anxiety within the context of foreign language education can be distinguished from trait anxiety and conceptualized as a "specific anxiety reaction" which presents "a major obstacle to be overcome in learning to speak another language" (p. 125). As rationale in the development of the contentious, but still widely used, Foreign Language Classroom Anxiety Scale (FLCAS), the authors assert that "the symptoms and consequences of foreign language anxiety" should "become readily identifiable to those concerned with language learning and teaching" (p. 125). Over three decades since this research was published, the domain of foreign language education has not conclusively identified the symptoms or consequences of the specific anxiety reaction, made distinctions between adaptive and maladaptive experiences of anxiety, nor clarified important differences between temporal mood states, worry, stress, intolerance of uncertainty and specific anxiety reactions. This lack of development is in part due to the methodologies used to confirm the presence of the concept and the challenge of attributing cause-effect relations. 


\section{Experiential Data}

Psychological problems such as anxiety concern emotion regulation or "the processes by which we influence which emotions we have, when we have them, and how we experience and express them" (Gross, 2002, p. 282). With a similar focus, Horwitz et al. (1986) contend that Foreign Language Classroom Anxiety (FLCA) is "a distinct complex of self-perceptions, beliefs, feelings and behaviours related to classroom learning arising from the uniqueness of the language learning process" (p. 128). This definition essentially concerns cognition in the form of self-perceptions, beliefs and feelings within a generalized environment, albeit one dramatically different from the new realities of language education being created through learning online. State anxiety can therefore be linked, as both cause and effect, to faulty perceptions of interpersonal threat and poor emotion regulation. The irrational beliefs and feelings generated under perception of interpersonal threat are either reappraised or suppressed by the individual, with the latter option having been found to reduce emotional memory recall (Richards and Gross, 2000). It has further been shown that the suppression of state anxiety not only impinges upon accurate memory recall but also results in the production of a greater physiological response to stressful stimuli (Malouff et al., 1992; Egloff et al., 2006).

This is problematic in that the experiential self-reports used to capture the cognitive aspects of the individual demand participants to recall information based on experience under the assumption that all individuals are equipped to perform this task to a high degree of accuracy. The reliability and validity of the data gathered are therefore beyond the immediate control of the researcher and dependent upon the subjectivities of the individual. Moreover, it is known that physiological processes can "influence emotion below the level of conscious awareness" which further "raises the question of whether emotion can be experienced or expressed with absent or attenuated consciousness" (Pace-Schott et al., 2019, p. 270). The information recalled in relation to generalized environmental stimuli necessitates that even when reliable cognitive recall is possible, the intensity, duration and momentary fluctuations within the experience are beyond the conscious awareness of most individuals (Schwerdtfeger, 2004). Harmon-Jones et al. (2016) assert that it is therefore inappropriate "to assume that a null effect on a self-report measure means that emotional processes were not involved in the psychological phenomena of interest. That is, the (often poor) measurement of emotion should not be conflated with emotion itself" (p. 2). Experiential self-report methods of data collection are are often thus negligent to the conceptual distinction between actual lived sensory experience and post-activity semantic recall (Robinson and Clore, 2002).

\section{Physiological Data}

Due to its evolutionary function in protecting individuals from situations perceived as threatening, anxiety is an ideal emotion for the incorporation of physiological measurement, especially as state anxiety can be experimentally induced. Physiological data provides a more reliable foundation for the attribution of cause- effect relations as it is "difficult for individuals to mask or control, which creates the possibility of more objectively gauging individuals' arousal" (Roos et al., 2021, p. 583). As one of a select few integrated assessments of state anxiety within foreign language education, Gregersen et al. (2014) triangulated physiological, idiodynamic, interview, and self-report data. However, the somewhat invasive procedure was technologically limited and promoted the misattribution of experimental stimuli. The process included recording a presentation (behavioural) and having participants self-rate their moment-by-moment anxiety 42 times over three-and-ahalf-minutes (experiential). Moreover, while the study made use of wearable technology to measure physiological responses, this was limited to heart rate. The use of heart rate monitors to assess state anxiety dates to the 1960s where studies used pulsemonitored heart rate as an indicator of test-anxiety (Harleston et al., 1965). It is now known that the use of heart rate as an indicator of autonomic nervous system arousal is problematic due to the combined role of the sympathetic and parasympathetic nervous systems (Cohen et al., 2000). For instance, an individual's heart rate is impacted by factors such as food consumption, caffeine intake, lack of sleep and general fatigue.

Further problems with the use of heart rate concern the fact that it cannot be fixed as a reliable indicator of emotional state or cognitive perception. Within the Gregersen et al. (2014) study inconsistencies were found between high heart rate readings and individual perceptions of anxiety. The authors explain how one participant "could have construed her racing heart as a debilitating sign of anxiety, thus initiating a downward spiral or negative-narrowing emotion; instead, she interpreted the accelerated heart rate as positive-broadening energy, which resulted in her channeling it into enthusiasm" (p. 586). Physiological arousal processed as indicative of anxiety may be reflective of excitement under the same experimental conditions dependent on the cognitive processing and emotion regulation of the individual. Brooks (2014) confirms that "anxiety and excitement have divergent effects on performance, but the experience of these two emotions is quite similar" (p. 1144). Roos et al. (2021) also caution that "different emotions (e.g., anxiety and excitement) can have the same physiological signatures". From this psycho-physiological insight further questions can be asked as to why the research literature on foreign language education has conclusively framed anxiety as a negative emotion (Rossi and Pourtois, 2012).

Two of the most prominent metrics used in the physiological assessment of anxiety are Heart Rate Variability (HRV) and Electrodermal Activity (EDA) (Croft et al., 2004; Blom et al., 2010; Nikolic et al., 2018; Sebastiao, 2021). As a reliable psychophysiological marker of health and well-being, HRV reflects an unobtrusive measure relating to the modulation of heart rate under instruction of the autonomic nervous system. HRV represents the variance in duration between heart beats or fluctuations in heart beat over a period of time measured in milliseconds. It is believed that low variation in duration between heart beats is indicative of the priming of the fight-or-flight response and is thus linked to greater levels of anxious arousal whereas a more relaxed individual might demonstrate a higher 


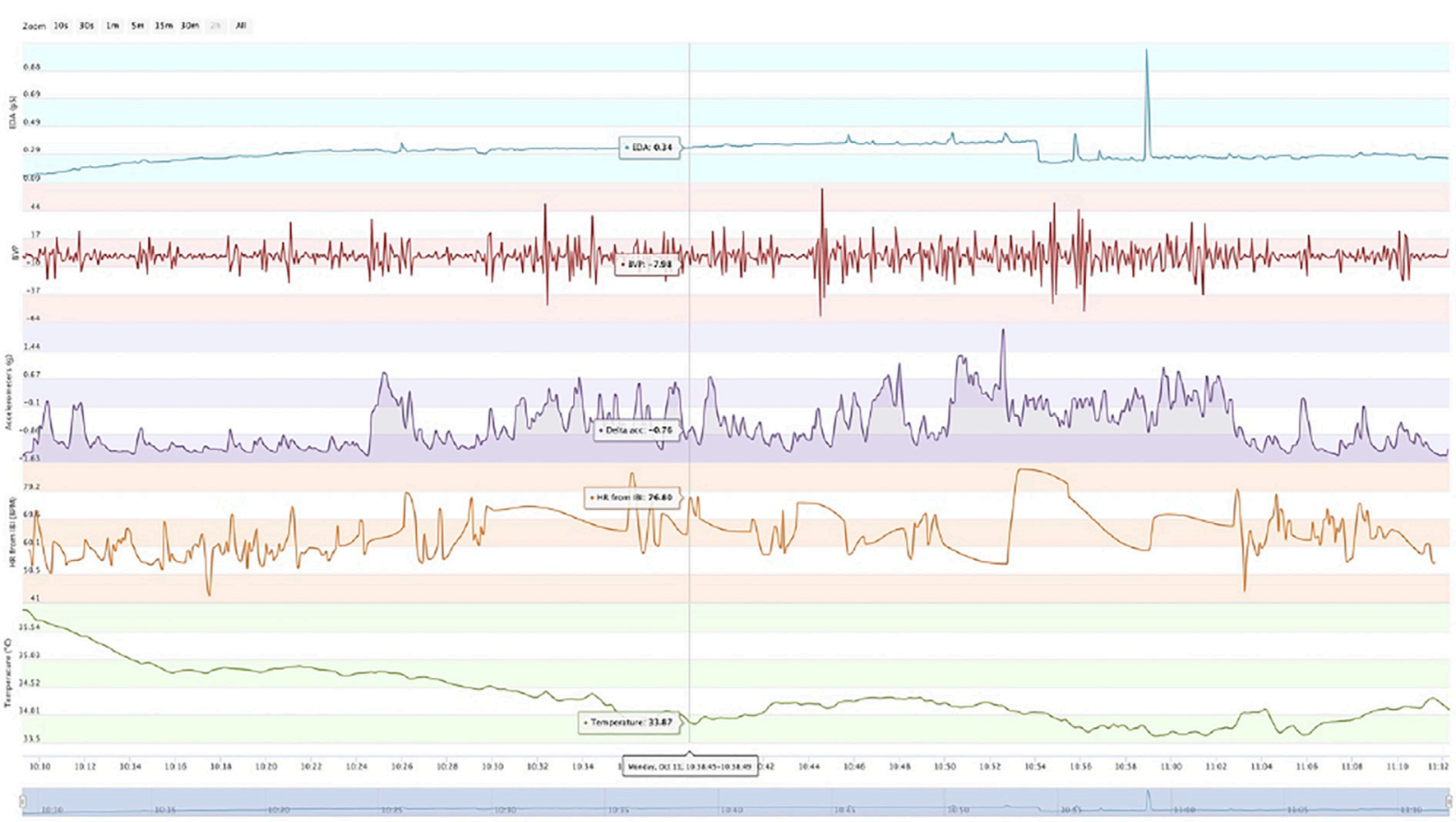

FIGURE 1 | An example of streamed data displayed in the E4 Connect repository.

variation in the duration between heart beats (Buccelletti et al., 2009). Reduced resting-state HRV has been linked to depression, alcoholism and pathological worry (Kemp et al., 2010; Quintana et al., 2013; Tully et al., 2013) while it has been reported that sufferers of anxiety are often characterized by a reduced HRV in comparison to non-anxiety sufferers. Held et al. (2021) report that "individuals suffering from an anxiety disorder are characterized by chronically low heart rate variability compared to healthy individuals during resting state conditions" (p. 1). HRV has further been linked to psychological well-being, cardiovascular health and mortality (Chalmers et al., 2014). In contrast to HRV, EDA detects autonomic changes in the electrical properties of skin which allows researchers to remove the parasympathetic contamination found within the use of heart rate monitors (Braithwaite et al., 2013). EDA has been described as providing an objective indication of arousal (Posada-Quintero and Chon, 2020). As a correlate of sympathetic nervous system activity, EDA concerns the volume of sweat produced by eccrine sweat glands. It is believed that the greater the volume of sweat present, the more electrical conductivity can be measured (Figner and Murphy, 2011). EDA has been used as a metric within studies of mathematics anxiety (Pizzie and Kraemer, 2021) and as a predictor of public speaking anxiety (Egloff et al., 2006; Sevinc, 2018; Lee et al., 2020).

\section{The Situation Specific Arousal Analyzer}

State specific anxiety is dynamic rather than static and momentary fluctuations in arousal can be expected even within the context of exposure to specific stimuli. Given that state anxiety corresponds to a specific stimulus, it is incumbent upon researchers to establish a clear start and end to accurately connect the stimulus to the response and avoid the misattribution of emotions to uncontrolled factors. However, within foreign language education research fixed durations including fluctuations across the timespan have not been documented due to methodological limitations and challenges in data processing. Recent advances in wearable health tracking devices have now created new opportunities for improvements to be made in terms of methodology and assessment. As one such device, the Empatica E4 wristband uses four censors which allow data to be "unobtrusively and continuously acquired while participants are performing the cognitive task" (Shackman et al., 2006, p. 42). Within the Empatica eco-system data from the $\mathrm{E} 4$ wristband can be captured in real-time and uploaded to the E4 Connect repository where the data files can then be downloaded into specialized software for further analysis. Figure 1 shows the streamed data displayed in the E4 Connect repository. For non-clinical researchers knowing how to process this data and how such data can then support the study of emotions in the classroom is challenging. The data uses a range of complex metrics and formulae which demand specialized reading often beyond the domain of foreign language education. From a technical perspective, it is therefore understandable as to why complex physiological data has not found its way into the methodological repertoire of studies into foreign language education anxiety until now.

Informed by the challenges outlined, the Situation Specific Arousal Analyzer (SSAA) application has been devised for use within the context of foreign language education to for the on-off 
TABLE 1 | An example of the tabulated data generated by the SSAA.

\begin{tabular}{|c|c|c|c|c|c|c|}
\hline \multirow[b]{2}{*}{ Metric } & \multirow[b]{2}{*}{ Baseline } & \multicolumn{5}{|c|}{ Five minute L2 spoken presentation } \\
\hline & & $0-60 \mathrm{~s}$ & $60-120 \mathrm{~s}$ & $120-180 \mathrm{~s}$ & $180-240 \mathrm{~s}$ & $240-300 \mathrm{~s}$ \\
\hline HR Mean (bpm) & 69.989 & 61.139 & 61.736 & 67.277 & 67.252 & 65.425 \\
\hline HR SD (bpm) & 5.21 & 5.322 & 5.979 & 9.522 & 3.027 & 1.696 \\
\hline NN Mean (ms) & $1,007.5$ & 1,050 & 997.396 & $1,011.837$ & $1,011.068$ & 995.924 \\
\hline NN SD (ms) & 78.502 & 45.793 & 61.588 & 72.242 & 79.603 & 69.274 \\
\hline VLF (ms2/Hz) & 991.945 & 73.596 & 669.639 & 353.985 & 849.354 & 749.903 \\
\hline $\mathrm{LF}(\mathrm{ms} 2 / \mathrm{Hz})$ & $1,083.81$ & 524.313 & 665.508 & $1,183.549$ & $1,122.134$ & $1,636.343$ \\
\hline $\mathrm{HF}(\mathrm{ms} 2 / \mathrm{Hz})$ & 834.375 & 355.717 & 790.207 & $1,015.255$ & 744.214 & 219.904 \\
\hline LF/HF & 1.299 & 1.474 & 0.842 & 1.166 & 1.508 & 7.441 \\
\hline PP SD1 (ms) & 49.973 & 26.865 & 44.672 & 44.115 & 62.704 & 30.205 \\
\hline PP SD2 (ms) & 99.685 & 57.905 & 70.824 & 92.491 & 95.01 & 95.51 \\
\hline EDA Mean (uS) & 0.183 & 0.253 & 0.263 & 0.276 & 0.302 & 0.312 \\
\hline EDA SD (uS) & 0.03 & 0.006 & 0.004 & 0.004 & 0.004 & 0.004 \\
\hline
\end{tabular}

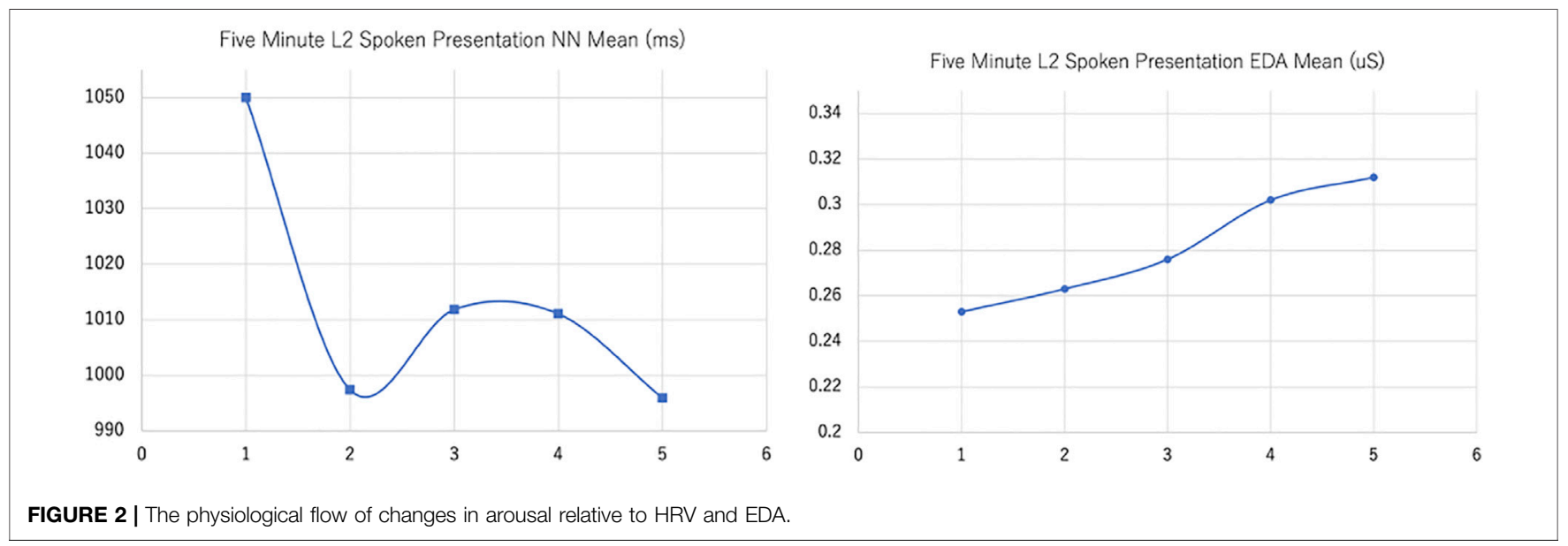

task physiological measurement and tracking of autonomic nervous system arousal. The SSAA application can be used through either the OS X or Windows platform and primarily focuses on the calculation of Heart Rate (HR), Heart Rate Variability (HRV) (time-domain methods, frequency-domain methods, non-linear domain methods) and Electrodermal Activity (EDA). The interface can be tailored to meet a range of experimental conditions focused on the micro analysis of arousal in time specific segments such as every few seconds during an L2 spoken presentation, or relative to longer macro periods of analysis such as across an entire classroom period. For the HRV time-domain, the beat-to-beat interval (NNMean) can be calculated up to once per $0.015625(1 / 64)$ second while for the EDAMean it is possible to capture data once per $0.25(1 / 4)$ second. The SSAA generates and exports these results as tabulated CSV files and visualizations. Table 1 provides an example of the tabulated output from the SSAA application based on the assessment of a five-minute L2 spoken presentation with measurements at 60 -s intervals.

The SSAA application also produces data outputs and visualizations for the HRV frequency-domain (low frequency (LF), high frequency (HF) and the ratio of LF and HF (LF/HF)) and for the HRV non-linear domain (SD1 and SD2 Poincaré
Plots) although these outputs are not anticipated to be as useful within the context of foreign language education due to their complexity. The tabulated data for each student can be plotted into more accessible line charts for the basis of analyzing the physiological flow of changes in arousal relative to each metric within and between students. Figure 2 shows the physiological flow for HRV mean and EDA mean for an individual L2 presentation across a five-minute duration.

While "there are some works in the literature regarding the physiological signals and their correlation with emotional experiences, the accuracy of the analysis seems to be dependent on the data set" (TaheriNejad and Pollreisz, 2017, p. 107) (see Blascovich and Tomaka, 1996; Huwe et al., 1998). The data quantification undertaken by the SSAA represents a significant innovation in accessible research methodology applicable to the study of foreign language education anxiety. The data generated through the SSAA permits correlations and affective relationships to be analyzed with other variables such as language acquisition and achievement (Dewaele and Li, 2020), emotional intelligence (Chen et al., 2021), intellectual humility (Moskowitz and Dewaele, 2020) and motivation and personality (Pan and Zhang, 2021). More importantly, the SSAA application supports the view of emotion as a multifaceted process inclusive 
of "components such as appraisal of the situation, action preparation, physiological responses, expressive behavior, and subjective feelings" (Scherer and Moors, 2019, p. 721). It provides greater access to a much-needed physiological component in the study of state specific anxiety and an overdue partner to the experiential self-report measures currently used.

\section{CONCLUSION}

This article has directed attention toward the need for more innovative assessments of state anxiety within foreign language education. The current situation and methodological lag can be likened to police assessments of driving under the influence of alcohol which are no longer informed by the experiential selfreports of the driver, but through the technological affordances provided in the form of an easily administrable breathalyzer device. In the same way that the physiological assessment of anxiety infers the emotion through the presence of autonomic nervous system arousal, the breathalyzer does not directly assess blood alcohol content, but rather estimates it through the amount of alcohol in the breath of an individual. To most readers it perhaps seems unimaginable to think of a contemporary police service which would now be reliant upon the experiential selfreports of the driver rather than combining such narratives with the more robust physiological assessments provided by technological innovation. This article has outlined why physiological data must now become a more prominent feature of research output if situation specific anxiety is to remain the most studied affective variable within the domain of foreign language education. It is acknowledged that "there is no 'gold standard' measure of emotional responding" (Mauss and

\section{REFERENCES}

Aida, Y. (1994). Examination of Horwitz, Horwitz, and Cope's Construct of Foreign Language Anxiety: The Case of Students of Japanese. Mod. Lang. J. 78 (2), 155-168. doi:10.1111/j.1540-4781.1994.tb02026.x

American Psychological Association (2021). Anxiety. Retrieved from: https://www. apa.org/topics/anxiety.

Blascovich, J., and Tomaka, J. (1996). "The Biopsychosocial Model of Arousal Regulation. Adv. Exp. Soc. Psychol. 28 (1), 1-51. doi:10.1016/S0065-2601(08) 60235-X

Blom, E. H., Olsson, E. M., Serlachius, E., Ericson, M., and Ingvar, M. (2010). Heart Rate Variability (HRV) in Adolescent Females with Anxiety Disorders and Major Depressive Disorder. Acta Paediatr. 99 (4), 604-611. doi:10.1111/j.16512227.2009.01657.x

Botes, E., Dewaele, J-M., and Greiff, S. (2020). The Foreign Language Classroom Anxiety Scale and Academic Achievement: An Overview of the Prevailing Literature and a Meta-Analysis. J. Psychol. Lang. Learn. 2, 26-56. Available at: https://jpll.org/index.php/journal/article/view/botesetal. doi:10.52598/jpll/2/ $1 / 3$

Braithwaite, J. J., Watson, D. G., Jones, R., and Rowe, M. (2013). A Guide for Analysing Electrodermal Activity (EDA) \& Skin Conductance Responses (SCRs) for Psychological Experiments. Psychophysiology 49, 1017-1034.

Brooks, A. W. (2014). Get Excited: Reappraising Pre-performance Anxiety as Excitement. J. Exp. Psychol. Gen. 143 (3), 1144-1158. doi:10.1037/a0035325

Buccelletti, E., Gilardi, E., Scaini, E., Galiuto, L., Persiani, R., Biondi, A., et al. (2009). Heart Rate Variability and Myocardial Infarction: Systematic Literature Review and Metanalysis. Eur. Rev. Med. Pharmacol. Sci. 13 (4), 299-307.
Robinson, 2009, p. 209) and the physiological data generated by the Empatica E4 and processed by the SSAA should ideally be used alongside experiential self-report measures and behavioural video recordings thus reflecting the tripartite profile of human emotion. The extent to which physiological data relates to experiential self-report measures or observed behavioural indications of arousal remains undocumented within the context of foreign language education and represents an exciting area of future research. It is hoped that innovations such as the SSAA encourage more non-clinical researchers to accommodate physiological data into their methodological repertoire to align the study of foreign language education anxiety with the technological opportunities now available.

\section{DATA AVAILABILITY STATEMENT}

The original contributions presented in the study are included in the article, further inquiries can be directed to the corresponding author.

\section{AUTHOR CONTRIBUTIONS}

The author confirms being the sole contributor of this work and has approved it for publication.

\section{FUNDING}

This research was supported by funding from the Japan Society for the Promotion of Science (No: 19K00765).

Chalmers, J. A., Quintana, D. S., Abbott, M. J., and Kemp, A. H. (2014). Anxiety Disorders Are Associated with Reduced Heart Rate Variability: A MetaAnalysis. Front. Psychiatry 5, 80. doi:10.3389/fpsyt.2014.00080

Chen, Z., Zhang, P., Lin, Y., and Li, Y. (2021). Interactions of Trait Emotional Intelligence, Foreign Language Anxiety, and Foreign Language Enjoyment in the Foreign Language Speaking Classroom. J. Multilingual Multicultural Develop., 1-21. doi:10.1080/01434632.2021.1890754

Cohen, H., Benjamin, J., Geva, A. B., Matar, M. A., Kaplan, Z., and Kotler, M. (2000). Autonomic Dysregulation in Panic Disorder and in post-traumatic Stress Disorder: Application of Power Spectrum Analysis of Heart Rate Variability at Rest and in Response to Recollection of Trauma or Panic Attacks. Psychiatry Res. 96 (1), 1-13. doi:10.1016/s0165-1781(00)00195-5

Croft, R. J., Gonsalvez, C. J., Gander, J., Lechem, L., and Barry, R. J. (2004). Differential Relations between Heart Rate and Skin Conductance, and Public Speaking Anxiety. J. Behav. Ther. Exp. Psychiatry 35 (3), 259-271. doi:10.1016/j. jbtep.2004.04.012

Dewaele, J.-M., and Moskowitz, S. (2020). The Role of Intellectual Humility in Foreign Language Enjoyment and Foreign Language Classroom Anxiety. Eurasian J. Appl. Linguistics 6 (3), 519-538. doi:10.32601/ejal.834664

Dewaele, J.-M., and Li, C. (2020). Emotions in Second Language Acquisition: A Critical Review and Research Agenda. Foreign Lang. World 196 (1), 34-49.

Dewaele, J.-M., and Pavelescu, L. M. (2021). The Relationship between Incommensurable Emotions and Willingness to Communicate in English as a Foreign Language: A Multiple Case Study. Innovation Lang. Learn. Teach. 15 (1), 66-80. doi:10.1080/17501229.2019.1675667

Dewaele, J.-M., Petrides, K. V., and Furnham, A. (2008). Effects of Trait Emotional Intelligence and Sociobiographical Variables on Communicative Anxiety and Foreign Language Anxiety Among Adult Multilinguals: A Review and 
Empirical Investigation. Lang. Learn. 58 (4), 911-960. doi:10.1111/j.1467-9922. 2008.00482.x

Dewaele, J. M., Chen, X., Padilla, A. M., and Lake, J. (2019). The Flowering of Positive Psychology in Foreign Language Teaching and Acquisition Research. Front. Psychol. 10, 2128. doi:10.3389/fpsyg.2019.02128

Dewaele, J. M. (2019). When Elephants Fly: The Lift-Off of Emotion Research in Applied Linguistics. Mod. Lang. J. 103 (2), 533-536. doi:10.1111/modl.12576

Egloff, B., Schmukle, S. C., Burns, L. R., and Schwerdtfeger, A. (2006). Spontaneous Emotion Regulation during Evaluated Speaking Tasks: Associations with Negative Affect, Anxiety Expression, Memory, and Physiological Responding. Emotion 6 (3), 356-366. doi:10.1037/1528-3542.6.3.356

Empatica Inc. (2021). E4 Wristband. Retrieved from https://www.empatica.com/ research/e4/.

Figner, B., and Murphy, R. O. (2011). "Using Skin Conductance in Judgment and Decision Making Research," in A Handbook of Process Tracing Methods for Decision Research: A Critical Review and User's Guide. Editors M. SchulteMecklenbeck, A. Kühberger, and R. Ranyard (New York: Psychology Press), 163-184.

Gregersen, T., and Horwitz, E. K. (2002). Language Learning and Perfectionism: Anxious and Non-anxious Language Learners' Reactions to Their Own Oral Performance. Mod. Lang. J. 86 (4), 562-570. doi:10.1111/1540-4781.00161

Gregersen, T., Macintyre, P. D., and Meza, M. D. (2014). The Motion of Emotion: Idiodynamic Case Studies of Learners' Foreign Language Anxiety. Mod. Lang. J. 98 (2), 574-588. doi:10.1111/modl.12084

Gross, J. J. (2002). Emotion Regulation: Affective, Cognitive, and Social Consequences. Psychophysiology 39 (3), 281-291. doi:10.1017/ s0048577201393198

Harleston, B. W., Smith, M. G., and Arey, D. (1965). Test-Anxiety Level, Heart Rate, and Anagram Problem Solving. J. Pers Soc. Psychol. 1 (6), 551-557. doi:10. 1037/h0021991

Harmon-Jones, C., Bastian, B., and Harmon-Jones, E. (2016). The Discrete Emotions Questionnaire: A New Tool for Measuring State Self-Reported Emotions. PLOS ONE 11 (8), e0159915. doi:10.1371/journal.pone.0159915

Held, J., Vîslă, A., Wolfer, C., Messerli-Bürgy, N., and Flückiger, C. (2021). Heart Rate Variability Change during a Stressful Cognitive Task in Individuals with Anxiety and Control Participants. BMC Psychol. 9, 44. doi:10.1186/s40359-02100551-4

Horwitz, E. K., Horwitz, M. B., and Cope, J. (1986). Foreign Language Classroom Anxiety. Mod. Lang. J. 70 (2), 125-132. doi:10.1111/j.1540-4781.1986.tb05256.x

Huwe, S., Hennig, J., and Netter, P. (1998). Biological, Emotional, Behavioral, and Coping Reactions to Examination Stress in High and Low State Anxious Subjects. Anxiety Stress Coping 11 (1), 47-65. doi:10.1080/10615809808249313

Kemp, A. H., Quintana, D. S., Gray, M. A., Brown, K. L. K., Felmingham, J. M., and Gatt, J. M. (2010). Impact of Depression and Antidepressant Treatment on Heart Rate Variability: A Review and Meta-Analysis. Biol. Psychiatry 67 (11), 1067-1074. doi:10.1016/j.biopsych.2009.12.012

Lee, H., Mandalapu, V., Kleinsmith, A., and Gong, J. (2020). "Distinguishing Anxiety Subtypes of English Language Learners towards Augmented Emotional Clarity," in Artificial Intelligence in Education. AIED 2020. Lecture Notes in Computer Science. Editors L. Bittencourt, M. Cukurova, K. Muldner, R. Luckin, and E. Millan (Cham: Springer), 12164, 157-161. doi:10.1007/978-3-03052240-7_29

Levenson, R. W. (2003). "Autonomic Specificity and Emotion," in Handbook of Affective Sciences. Editors R. J. Davidson, K. R. Scherer, and H. H. Goldsmith (Oxford University Press), 212-224.

Li, C. (2019). A Positive Psychology Perspective on Chinese EFL Students' Trait Emotional Intelligence, Foreign Language Enjoyment and EFL Learning Achievement. J. Multilingual Multicultural Develop. 41 (3), 246-263. doi:10. 1080/01434632.2019.1614187

Li, C., Dewaele, J.-M., and Jiang, G. (2019). The Complex Relationship between Classroom Emotions and EFL Achievement in China. Appl. Linguistics Rev. 11 (3), 485-510. doi:10.1515/applirev-2018-0043

Li, C., Huang, J., and Li, B. (2021). The Predictive Effects of Classroom Environment and Trait Emotional Intelligence on Foreign Language Enjoyment and Anxiety. System 96, 102393. doi:10.1016/j.system.2020.102393

MacIntyre, P. D. (2017). "2. An Overview of Language Anxiety Research and Trends in its Development," in New Insights into Language Anxiety: Theory, Research and Educational Implications. Editors C. Gkonou,
M. Daubney, and J-M. Dewaele (Bristol: Multilingual Matters), 11-30. doi:10.21832/9781783097722-003

MacIntyre, P. D., and Gardner, R. C. (1994). The Subtle Effects of Language Anxiety on Cognitive Processing in the Second Language. Lang. Learn. 44 (2), 283-305. doi:10.1111/j.1467-1770.1994.tb01103.x

Malouff, J. M., Schutte, N. S., and McClelland, T. (1992). Examination of the Relationship between Irrational Beliefs and State Anxiety. Personal. Individual Differences 13 (4), 451-456. doi:10.1016/0191-8869(92)90074-Y

Mauss, I. B., and Robinson, M. D. (2009). Measures of Emotion: A Review. Cogn. Emot. 23 (2), 209-237. doi:10.1080/02699930802204677

Nikolić, M., Aktar, E., Bögels, S., Colonnesi, C., and de Vente, W. (2018). Bumping Heart and Sweaty Palms: Physiological Hyperarousal as a Risk Factor for Child Social Anxiety. J. Child. Psychol. Psychiatr. 59 (2), 119-128. doi:10.1111/jcpp. 12813

Onwuegbuzie, A. J., Bailey, P., and Daley, C. E. (1999). Factors Associated with Foreign Language Anxiety. Appl. Psycholinguistics 20 (2), 217-239. doi:10.1017/ S0142716499002039

Pace-Schott, E. F., Amole, M. C., Aue, T., Balconi, M., Bylsma, L. M., Critchley, H., et al. (2019). Physiological Feelings. Neurosci. Biobehavioral Rev. 103, 267-304. doi:10.1016/j.neubiorev.2019.05.002

Pan, C., and Zhang, X. (2021). A Longitudinal Study of Foreign Language Anxiety and Enjoyment. Lang. Teach. Res. doi:10.1177/1362168821993341

Pizzie, R. G., and Kraemer, D. (2021). The Association between Emotion Regulation, Physiological Arousal, and Performance in Math Anxiety. Front. Psychol. 12, 639448. doi:10.3389/fpsyg.2021.639448

Posada-Quintero, H. F., and Chon, K. H. (2020). Innovations in Electrodermal Activity Data Collection and Signal Processing: A Systematic Review. Sensors 20 (2), 479. doi:10.3390/s20020479

Quintana, D. S., McGregor, I. S., Guastella, A. J., Malhi, G. S., and Kemp, A. H. (2013). A Meta-Analysis on the Impact of Alcohol Dependence on ShortTerm Resting-State Heart Rate Variability: Implications for Cardiovascular Risk. Alcohol. Clin. Exp. Res. 37 (S1), 23-29. doi:10. $1111 / \mathrm{j} .1530-0277.2012 .01913 . x$

Richards, J. M., and Gross, J. J. (2000). Emotion Regulation and Memory: The Cognitive Costs of Keeping One's Cool. J. Personal. Soc. Psychol. 79 (3), 410-424. doi:10.1037//0022-3514.79.3.410

Robinson, M. D., and Clore, G. L. (2002). Belief and Feeling: Evidence for an Accessibility Model of Emotional Self- Report. Psychol. Bull. 128 (6), 934-960. doi:10.1037/0033-2909.128.6.934

Robinson, O. J., Vytal, K., Cornwell, B. R., and Grillon, C. (2013). The Impact of Anxiety upon Cognition: Perspectives from Human Threat of Shock Studies. Front. Hum. Neurosci. 7, 203. doi:10.3389/fnhum.2013.00203

Roos, A. L., Goetz, T., Voracek, M., Krannich, M., Bieg, M., Jarrell, A., et al. (2021). Test Anxiety and Physiological Arousal: A Systematic Review and MetaAnalysis. Educ. Psychol. Rev. 33, 579-618. doi:10.1007/s10648-020-09543-z

Rossi, V., and Pourtois, G. (2012). Transient State-dependent Fluctuations in Anxiety Measured Using STAI, POMS, PANAS or VAS: A Comparative Review. Anxiety, Stress, and Coping 25 (6), 603-645. doi:10.1080/10615806. 2011.582948

Scherer, K. R., and Moors, A. (2019). The Emotion Process: Event Appraisal and Component Differentiation. Annu. Rev. Psychol. 70, 719-745. doi:10.1146/ annurev-psych-122216-011854

Schwerdtfeger, A. (2004). Predicting Autonomic Reactivity to Public Speaking: Don't Get Fixed on Self-Report Data!. Int. J. Psychophysiology 52 (3), 217-224. doi:10.1016/j.ijpsycho.2003.10.008

Sebastiao, R. (2021). "Classification of Anxiety Based on EDA and HR," in IoT Technologies for HealthCare. HealthyIoT 2020. Lecture Notes of the Institute for Computer Sciences, Social Informatics and Telecommunications Engineering. Editors R. Goleva, N. R. C. Garcia, and I. M Pires (Cham: Springer), 360. doi:10. 1007/978-3-030-69963-5_8

Sevinc, Y. (2018). Language Anxiety in the Immigrant Context: Sweaty Palms? Int. J. Bilingualism 22 (6), 717-739. doi:10.1177/1367006917690914

Shackman, A. J., Sarinopoulos, I., Maxwell, J. S., Pizzagalli, D. A., Lavric, A., and Davidson, R. J. (2006). Anxiety Selectively Disrupts Visuospatial Working Memory. Emotion 6 (1), 40-61. doi:10.1037/1528-3542.6.1.40

Spielberger, C. D., Gorsuch, R. L., Lushene, R., Vagg, P. R., and Jacobs, G. A. (1983). Manual for the State-Trait Anxiety Inventory. Palo Alto: Consulting Psychologists Press. 
Swain, M. (2013). The Inseparability of Cognition and Emotion in Second Language Learning. Lang. Teach. 46, 195-207. doi:10.1017/ S0261444811000486

TaheriNejad, N., and Pollreisz, D. (2017). "Assessment of Physiological Signals during Happiness, Sadness, Pain or Anger," in Wireless Mobile Communication and Healthcare. MobiHealth 2016. Lecture Notes of the Institute for Computer Sciences, Social Informatics and Telecommunications Engineering. Editors P. Perego, G. Andreoni, and G. Rizzo (Cham: Springer), 192. doi:10.1007/ 978-3-319-58877-3_14

Tully, P. J., Cosh, S. M., and Baune, B. T. (2013). A Review of the Affects of Worry and Generalized Anxiety Disorder upon Cardiovascular Health and Coronary Heart Disease. Psychol. Health Med. 18 (6), 627-644. doi:10.1080/13548506. 2012.749355

Zheng, Y., and Cheng, L. (2018). How Does Anxiety Influence Language Performance? from the Perspectives of Foreign Language Classroom Anxiety and Cognitive Test Anxiety. Lang. Test. Asia 8, 13. doi:10.1186/s40468-018-0065-4
Conflict of Interest: The author declares that the research was conducted in the absence of any commercial or financial relationships that could be construed as a potential conflict of interest.

Publisher's Note: All claims expressed in this article are solely those of the authors and do not necessarily represent those of their affiliated organizations, or those of the publisher, the editors, and the reviewers. Any product that may be evaluated in this article, or claim that may be made by its manufacturer, is not guaranteed or endorsed by the publisher.

Copyright $\odot 2022$ Rivers. This is an open-access article distributed under the terms of the Creative Commons Attribution License (CC BY). The use, distribution or reproduction in other forums is permitted, provided the original author(s) and the copyright owner(s) are credited and that the original publication in this journal is cited, in accordance with accepted academic practice. No use, distribution or reproduction is permitted which does not comply with these terms. 